\title{
Hypothyroidism Causes Endoplasmic Reticulum Stress in Adult Rat Hippocampus: A Mechanism Associated with Hippocampal Damage
}

\author{
Alejandra Paola Torres-Manzo $\left(\mathbb{D},{ }^{1,2}\right.$ Margarita Franco-Colín $\left(\mathbb{D},{ }^{1}\right.$ Vanessa Blas-Valdivia $\left(\mathbb{D},{ }^{2}\right.$ \\ Marisol Pineda-Reynoso, ${ }^{3}$ and Edgar Cano-Europa $\mathbb{D i}^{1}$ \\ ${ }^{1}$ Instituto Politécnico Nacional, Laboratorio de Metabolismo I, Departamento de Fisiología "Dr. Mauricio Russek Berman”, Escuela \\ Nacional de Ciencias Biológicas, Av. Wilfrido Massieu s/n, Esq. Manuel L. Stampa, Unidad Profesional Adolfo López Mateos, Del. \\ Gustavo A. Madero, 07738 Ciudad de México, Mexico \\ ${ }^{2}$ Instituto Politécnico Nacional, Lab. Neurobiología, Departamento de Fisiología "Dr. Mauricio Russek Berman”, Escuela Nacional de \\ Ciencias Biológicas, Av. Wilfrido Massieu s/n, Esq. Manuel L. Stampa, Unidad Profesional Adolfo López Mateos, Del. Gustavo A. \\ Madero, 07738 Ciudad de México, Mexico \\ ${ }^{3}$ Instituto Politécnico Nacional, Escuela Superior de Medicina, Plan de San Luis y Díaz Mirón s/n, 11340 Ciudad de México, Mexico
}

Correspondence should be addressed to Edgar Cano-Europa; edgarcanoeuropa@yahoo.com.mx

Received 21 November 2017; Revised 14 February 2018; Accepted 1 March 2018; Published 20 March 2018

Academic Editor: Victor M. Victor

Copyright (c) 2018 Alejandra Paola Torres-Manzo et al. This is an open access article distributed under the Creative Commons Attribution License, which permits unrestricted use, distribution, and reproduction in any medium, provided the original work is properly cited.

\begin{abstract}
Thyroid hormones (TH) are essential for hippocampal neuronal viability in adulthood, and their deficiency causes hypothyroidism, which is related to oxidative stress events and neuronal damage. Also, it has been hypothesized that hypothyroidism causes a glucose deprivation in the neuron. This study is aimed at evaluating the temporal participation of the endoplasmic reticulum stress (ERE) in hippocampal neurons of adult hypothyroid rats and its association with the oxidative stress events. Adult Wistar male rats were divided into euthyroid and hypothyroid groups. Thyroidectomy with parathyroid gland reimplementation caused hypothyroidism at three weeks postsurgery. Oxidative stress, redox environment, and antioxidant enzyme markers, as well as the expression of the ERE through the pathways of PERK, ATF6, and IRE1, were evaluated at the 3rd and 4th weeks postsurgery. We found a rise in ROS and nitrite production; also, catalase increased and glutathione peroxidase diminished their activities. These events promote an enhancement of the lipoperoxidation, as well as of $\gamma$-GT, myeloperoxidase, and caspase 3 activities. With respect to ERE, there were ATF6, IRE1, and GADD153 overexpressions with a reduction in mitochondrial activity and $\mathrm{GSH}^{2} / \mathrm{GSSG}$ ratio. We conclude that the endoplasmic reticulum stress might play a pivotal role in the activation of hypothyroidism-induced hippocampal cell death.
\end{abstract}

\section{Introduction}

Hypothyroidism is a clinical condition in which thyroid hormone $(\mathrm{TH})$ release of the thyroid gland is low, and it is not enough to satisfy the demand of the tissues [1]. TH deficiencies lead to a broad spectrum of clinical manifestations, including neurologic symptoms like memory impairment, difficulty concentrating, and depression $[2,3]$. These alterations are directly linked with the hippocampus, which is especially sensitive to thyroid hormone deprivation [4-6].
Several studies have shown that hypothyroidism leads to neuronal death in the hippocampus [7]. The entire mechanism is not still well understood, but it involves the presence of oxidative stress [6] and the activation of the N-methyl-Daspartate receptor- (NMDAR-) mediated glutamate excitotoxicity [5]. However, the biological events mentioned above are probably an activation consequence of several mechanisms; one of them can be the endoplasmic reticulum stress (ERE). The ERE is defined as the accumulation of misfolded or not folded proteins and their aggregates in the lumen of 
this organelle. The ERE triggers an adaptive response called the unfolded protein response (UPR) which is developed to restore the ER homeostasis, and also it allows the cell to attenuate general translation. The endoplasmic reticulum increases the synthesis of chaperones and other proteins involved in the UPR and eliminates the defective proteins by the endoplasmic reticulum-associated protein degradation (ERAD) mechanism [8]. When ERE is not alleviated, it becomes chronic and leads to the activation of caspase 12activated cell death [9]. On the other hand, it has been demonstrated that nutrient deprivation (mainly oxygen and glucose) is one of the most potent ERE triggers [10], since it impairs $\mathrm{N}$-linked protein glycosylation and diminishes the ATP obtaining. The processes mentioned before lead to a decrease in the amount of energy available to maintain the oxidizing environment needed to the correct formation of disulfide bonds and the proper folding of proteins in the endoplasmic reticulum (ER). Thus, the ERE triggers lead to ER overload of misfolded and not folded proteins and the consequent activation of the UPR[11].

A relation between hypothyroidism and ERE has not yet been studied. However, it is well known that hypothyroidism causes a reduction in the brain blood flow [12], and also it decreases the expression of glucose transporter GLUT1 on the blood-brain barrier [13], which can lead to a decrease in the brain glucose input. Also, hypothyroid subjects usually present with insulin resistance $[14,15]$, a condition that might provoke a reduction in glucose intake from neurons and glia, especially in the hippocampus, where there is a high expression of insulin-dependent GLUT4 transporter [16]. Therefore, we believe that there must be an association between the activation of endoplasmic reticulum stress and hypothyroidism-caused neuronal damage in the hippocampus. This study is aimed at evaluating the temporal participation of the endoplasmic reticulum stress (ERE) in hippocampal neurons of adult hypothyroid rats and its association with the oxidative stress events.

\section{Methods}

2.1. Animals and Housing and Experimental Design. Fortyeight male Wistar rats (200-250 g) of our care facilities were kept in acrylic cages $(80 \times 30 \times 20 \mathrm{~cm})$ in a cooled-regulated room $\left(20 \pm 1^{\circ} \mathrm{C}\right)$ with water and food ad libitum, light cycles of $12 / 12 \mathrm{~h}$, and relative humidity of $40-60 \%$. All procedures were realized according to Mexican laws and codes in the seventh title of the General Law of Health regarding health research and NOM-062-ZOO-1999 for the handle of laboratory animals, and these procedures were also approved by the ENCB-IPN Bioethics committee (CEI-ENCB-021/2014).

Animals were initially divided into two groups: hypothyroid (Hypo; $n=24$ ) and euthyroid (Eu; $n=24$ ). Hypothyroidism was induced by a surgical removal of the thyroid gland with reimplantation of the parathyroid gland in the pectoral muscle, as previously described by Pineda-Reynoso et al. [17]. A false thyroidectomy, with the same surgical and postsurgical cares, was performed on euthyroid animals. After surgery, each group was subdivided into the third week and fourth week subgroups, according to the times they were sacrificed.

2.2. Thyroid State Determinations. Rectal temperature of all groups was measured three times a week at the same hour in the morning $(0900 \mathrm{~h})$, using a digital thermometer (BD Diagnostics), just like body weight. Both variables were used as indirect measures of the thyroid state of rats, while thyroid hormones $\left(T_{3}\right.$ and $\left.T_{4}\right)$ were quantified in the serum at the different times of sacrifice by ELISA, using commercial kits (Diagmex, México), and were used to establish thyroid state of rats at that time.

2.3. Sacrifice of Animals and Sampling. After the different test times, animals were beheaded. Immediately, the blood and the brains were obtained and separated. Four brains of each group were fixed in $4 \%$ PBS paraformaldehyde (PFH), while the hippocampus was dissected from the remaining eight brains. The hippocampus was immediately frozen and stored at $-70^{\circ} \mathrm{C}$ until use.

2.4. General Preparation of the Samples. The dissected hippocampus was homogenized in $500 \mu \mathrm{L} \cdot 10 \mathrm{mM}$ phosphate buffer $(\mathrm{pH} 7.4)$ and was used to perform all the biochemical determinations, the Western blot, and the mitochondrial function and caspase 3 activity assays.

2.5. Biochemical Determinations. The quantification of oxidative stress marker reactive oxygen species (ROS) and the lipid peroxidation assay were performed as previously described $[18,19]$, nitrites were assessed by Griess reaction, as previously described by Sastry et al. [20], and myeloperoxidase (MPO) activity was assessed by Fietz et al.'s method [21].

The activity of antioxidant enzymes was assessed by spectrophotometric techniques. For catalase activity, we followed the spectrophotometric method previously described by Cano-Europa et al. [22], the glutathione peroxidase (GPX) activity was measured by Hafeman et al.'s technique [23], total superoxide dismutase (SOD) activity was assessed by Crapo et al.'s method [24], and glutathione reductase (GR) activity was measured using the method proposed by Askelöf et al. [25].

The gamma-glutamyl transpeptidase ( $\gamma$-GT) activity was determined by a commercial kit ( $\gamma$-GT-LQ, Spinreact, Spain), according to the manufacturer's instructions.

The markers of redox environment reduced glutathione (GSH) and oxidized glutathione (GSSG) and were assessed by a spectrofluorometrical method, as previously described [22]. The $\mathrm{GSH}^{2} / \mathrm{GSSG}$ ratio was assessed according to Schafer and Buettner [26].

2.6. Western Blot Assay. Western blot samples were prepared as follows: one hundred microliters of homogenate was taken and mixed in Eppendorf tubes containing $30 \mu \mathrm{L}$ of a Complete Protease Inhibitor Cocktail ${ }^{\circledR}$ (Sigma-Aldrich, St. Louis Missouri, USA) in lysis buffer, and $130 \mu \mathrm{L}$ of charge buffer was added. The samples were homogenized in a vortex and then placed in a boiling water bath for 3 minutes. The samples were kept at $-20^{\circ} \mathrm{C}$ until use. 
Endoplasmic reticulum stress markers, IRE1 (Abcam, UK; ab37073), ATF6 $\alpha$, GADD34, GADD153, XBP-1 (Santa Cruz Biotechnology, Dallas, Texas, USA; sc-22799, sc-8327, sc-575, and sc-7160, resp.), ATF4 (Biorbyt, Cambridge, UK; orb-129518), and caspase 12 (Millipore, Billerica, Massachusetts, USA AB3613), were determined by Western blot analysis. Briefly, $50 \mu \mathrm{g}$ of protein was charged in $10 \%$ polyacrylamide gels and separated by electrophoresis. After that, proteins of gels were electrotransferred to PVDF membranes in a semidry chamber. Transferred membranes were blocked for $1 \mathrm{~h}$ under constant stirring, in blocking buffer (PBST; 0.05\% tween 20 in saline phosphate buffer containing $5 \%$ low-fat milk Svelty $\left.{ }^{\circledR}\right)$. Blocked membranes were incubated overnight in blocking buffer containing the primary antibodies diluted at 1:500 (ATF6 $\alpha$, GADD34, GADD153, XBP-1, and caspase 12), 1:1000 (IRE1), and 1:2000 (CREB2) at $4^{\circ} \mathrm{C}$. After incubation, membranes received three 20 min washes with fresh PBST. Washed membranes were then incubated in blocking buffer containing $1: 1000$ diluted secondary antibody (HPR-conjugated goat antirabbit or rabbit anti-goat; Life technologies, Rockford, Illinois, USA; 65-6120 and 611620, resp.) for $1 \mathrm{~h}$ at room temperature, under constant stirring. Membranes were washed again, and finally, protein bands were revealed in photographic plates (JUAMA, México) using Luminata ${ }^{\mathrm{TM}}$ Forte $^{\circledR}$ (Millipore, Billerica, Massachusetts, USA). Protein $\beta$-actin expression was used as a charge control and constitutive protein (Santa Cruz Biotechnology, Dallas Texas, USA; sc-1615, dilution: $1: 4000)$. Optical density (OD) of all the bands was analyzed by ImageJ program version 1.51p (NIH, Bethesda, Maryland, USA), according to program specifications. Protein OD is expressed as a protein $/ \beta$-actin index.

2.7. Immunofluorescence Assay. PFH-fixed brains were processed by a conventional paraffin-embedded technique. Paraffin cubes were cut in a microtome to obtain $5 \mu \mathrm{m}$ tissue laminae. The hippocampus region was localized at -1.8 and -2.3 with respect to Bregma, according to Paxinos and Watson [27]. We used the immunofluorescence test to detect the expression of ERE protein peIF $2 \alpha$. Briefly, tissue sections were deparaffinized and blocked with $1 \%$ bovine albumin (Sigma-Aldrich) in Tris-saline buffer (TBST) ( $\mathrm{pH} 7.6)$, for one hour. After that, the slices were incubated with $1: 200$ diluted anti-peIF2 $\alpha$ antibody (Santa Cruz Biotechnology, Dallas, Texas, USA; sc-12412) at $4^{\circ} \mathrm{C}$ overnight. After incubation, we performed three $10 \mathrm{~min}$ TBST washes. Then, the slices were incubated with a donkey anti-goat-FITC-coupled antibody (1:5000, Abcam, UK; ab8861) for one hour in darkness. Tissue laminae were washed again, and the immunofluorescence was detected with a fluorescence microscopy. Images obtained were analyzed with the program ImageJ version $1.51 \mathrm{p}$.

2.8. Mitochondrial Function Test and Caspase 3 Activity. Mitochondrial activity was measured as previously described by Elinos-Calderón et al. [28] modified by us, as we used p-iodonitrotetrazolium violet (INT) instead of tetrazolium blue. Mitochondrial function is expressed as \% of INT reduction, with respect to the euthyroid group.
Caspase 3 activity was assessed by using a commercial colorimetric assay kit (Millipore, Billerica, Massachusetts, USA; APT165), according to the manufacturer's instructions. Caspase activity is expressed as $\mu \mathrm{mol}$ of PNA released $/ \mathrm{mg}$ protein/min.

2.9. Statistical Analysis. All data were analyzed through the Sigma Stat program version 3.5 (Systat Software Inc., San Jose, California, USA) and were presented as mean \pm standard error of the mean. A repeated measures two-way analysis of variance (RM two-way ANOVA) was performed for rectal temperature, while the rest of the results were analyzed by two-way ANOVA. All analyses considered the thyroid state (euthyroid or hypothyroid) and time (third week or fourth week) as factors, followed by a Student-NewmanKeuls post hoc test. Values that presented a $P<0.05$ were considered statistically different.

\section{Results}

3.1. Effect of Thyroidectomy on Rectal Temperature and Serum $T_{3}$ and $T_{4}$ Levels. Figure 1 shows that thyroidectomy decreases rectal temperature (Figure 1(a)) and serum thyroid hormones $\mathrm{T}_{3}$ (Figure $1(\mathrm{~b})$ ) and $\mathrm{T}_{4}$ (Figure $1(\mathrm{c})$ ) at both third and fourth weeks, with respect to sham animals. These results allowed us to be sure that thyroidectomized rats presented signs of hypothyroidism.

3.2. Hypothyroidism Causes Oxidative Stress and Modifies the Antioxidant Enzyme Activity and the Redox Environment. Figure 2 shows that hypothyroid rats presented an increased production of ROS (Figure 2(a)) and nitrites (Figure 2(c)) at the third week, followed by a rise in lipid peroxidation (Figure 2(b)) and a higher myeloperoxidase activity at the fourth week postthyroidectomy (Figure 2(d)). Increased oxidant products were not successfully neutralized by antioxidant enzymes catalase, SOD, GPX, and GR (Figures 3(a)-3(d), resp.), since only catalase activity increased at the third week and GPX activity was diminished at both times evaluated.

Table 1 data shows a reduction in GSH concentration with a $\mathrm{GSH}^{2} / \mathrm{GSSG}$ ratio reduction for hypothyroid animals at the fourth week. These modifications could not be compensated by the progressive increased $\gamma$-GT activity.

All modifications in the quantification of oxidative products, the antioxidant enzyme activities, and redox environment marker modifications demonstrate the presence of oxidative stress at the fourth week and the diminished capability of the cell to maintain the redox environment in hypothyroid animals.

3.3. Hypothyroidism Causes Endoplasmic Reticulum Stress. To probe that hypothyroidism may induce endoplasmic reticulum stress in the hippocampus, we determined the expression of key molecular players involved in PERK, ATF6, and IRE1 branches of the UPR.

Figure 4 integrates the results of the expression of the PERK branch, which was measured through the expression of peIF2 $\alpha$ (Figures 4(a)-4(e)), CREB2 (Figure 4(f)), and GADD34 (Figure 4(g)). Apparently, this response is at least not fully activated, due to phosphorylation of eIF2 $\alpha$ which 


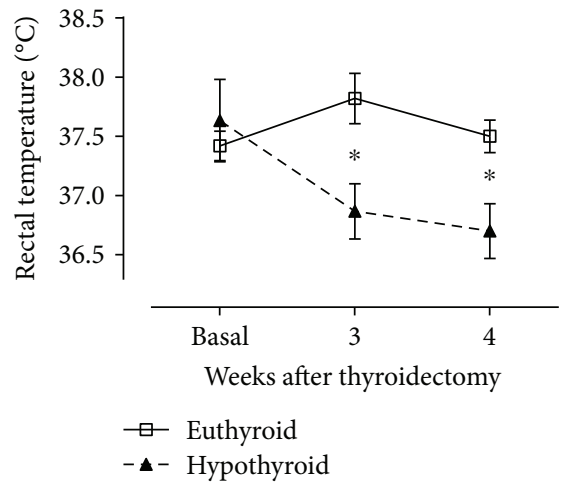

(a)

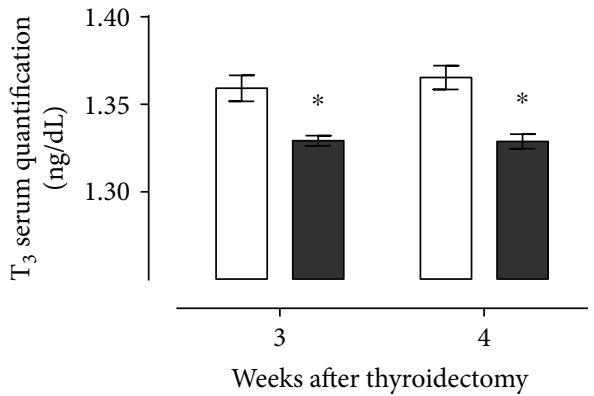

(b)

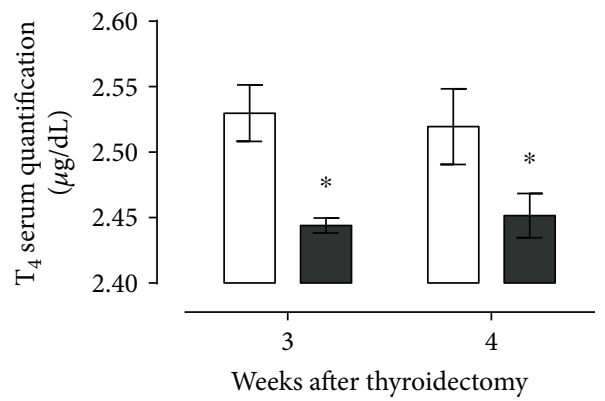

(c)

Figure 1: Effect of thyroidectomy on rectal temperature (a), $\mathrm{T}_{3}$ serum quantification (b), and $\mathrm{T}_{4}$ serum quantification (c) of rats at different times after surgery. Data are expressed as the mean \pm SEM. ${ }^{*} P<0.05$ versus the euthyroid group $(n=24)$.

was probably inhibited by a protein different from GADD34, since the expression of both markers is not increased at any evaluated time, with respect to euthyroid animals, and just presented a light increase compared to the response in the hypothyroid group at the third week. GADD34 expression is also diminished at the third week if we compare such expression with that of euthyroid animals at the same evaluated time. Besides the nondifferent phosphorylation of eIF2 $\alpha$, CREB2 expression was higher than that of its euthyroid control at the fourth week, indicating the partial activity of PERK response.

The expression of the second and third branches of the UPR, mediated by ERE sensors ATF6 and IRE1 $\alpha$, showed an increase in the hypothyroid group at the fourth week, as we show in Figures 5(a) and 5(b). The expression of XBP1 (Figure 5(c)) was not modified during hypothyroidism, indicating that ribonuclease activity of IRE1 $\alpha$ was not increased as a response for this condition.

\subsection{Endoplasmic Reticulum Stress Leads to Hippocampal} Neuron Death. Due to the higher expression of CREB2 and ATF6 in the hypothyroid group at the fourth week, we evaluated the expression of GADD153 (Figure 6(a)) and found that this protein was less expressed in hypothyroid animals at the third week but had a rise at the fourth week.

Given the proapoptotic function of GADD153, we also evaluated some ER-related death proteins and the mitochondrial activity of hippocampal cells and found that the hypothyroid state induces the expression of the ER membrane-associated caspase 12 at both times evaluated
(Figure 6(b)). Mitochondrial function was not different between euthyroid and hypothyroid rats at the third week but presented a $50 \%$ decay in hypothyroid animals at the fourth week (Figure 6(c), indicating the damage in this organelle. Finally, we evaluated the activity of the effector protein caspase 3 that, as we expected, presented a practically three-fold increase in hypothyroid animals at the fourth week (Figure 6(d)), demonstrating that hippocampal neurons activated cell death mechanisms mediated, at least partially, by the activation of ER caspase 12 .

\section{Discussion}

Several studies attribute hypothyroidism-induced neuronal death in the hippocampus to glutamate excitotoxicity mediated by $\mathrm{N}$-methyl-D-aspartate receptors (NMDAR). This hypothesis is supported because hypothyroidism causes a reduction in $\mathrm{Na}^{+} / \mathrm{K}^{+}$ATPase expression and activity in the membrane of hippocampal neurons [29]. This event probably modifies the neuronal rest potential which finally leads to the activation of NMDA receptors that import calcium ions to the neuron cytoplasm and activate calcium-sensitive kinases, inducing mitochondrial damage and leading to apoptosis [30]. Besides that this is one of the most accepted mechanisms of hypothyroidism-induced hippocampal neuronal death, it cannot be the only one, or at least, not the primary inducer for several reasons, one of which is that other works have found that glutamate synthesis and release are diminished in hypothyroidism [31, 32]. Based on the evidence described before, we developed the hypothesis that 


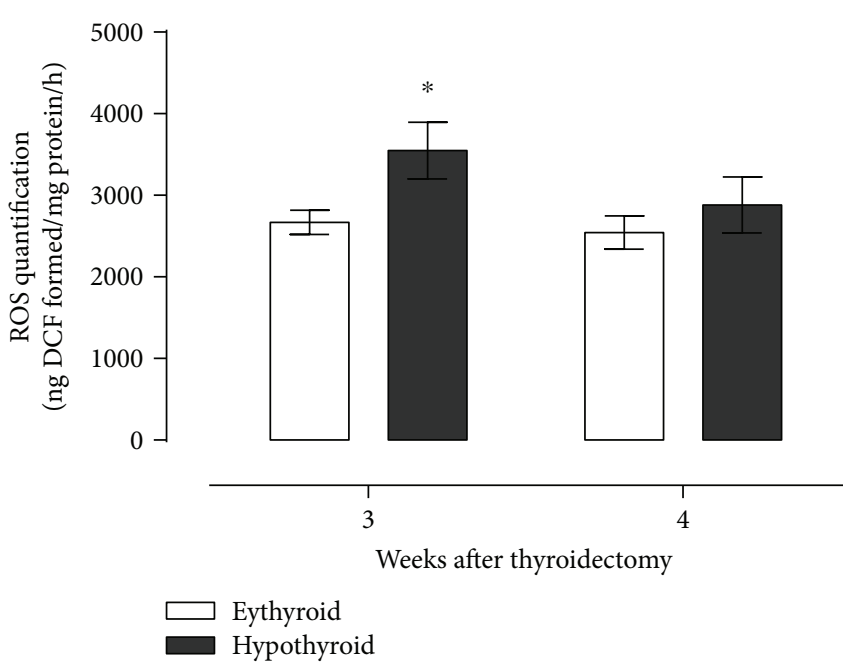

(a)

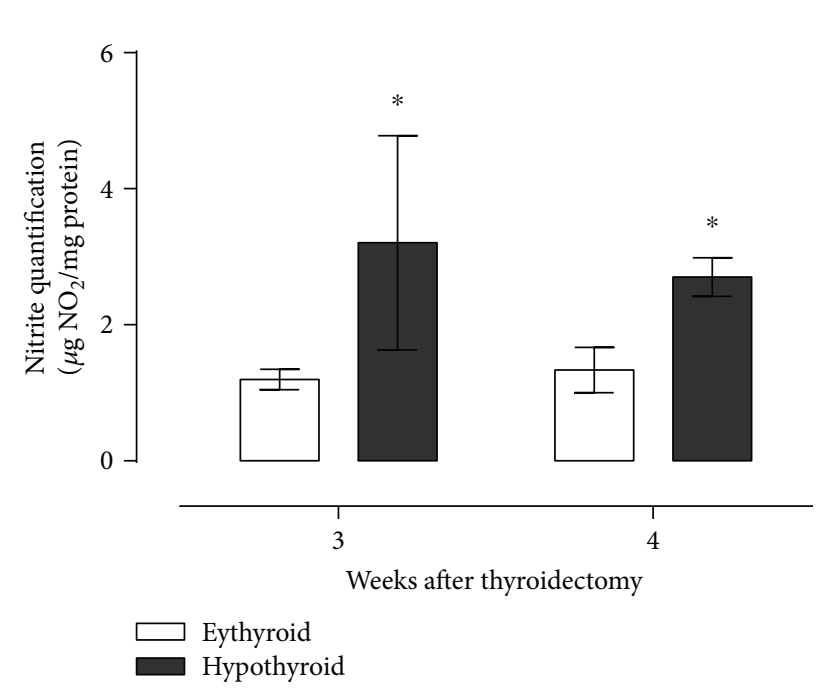

(c)

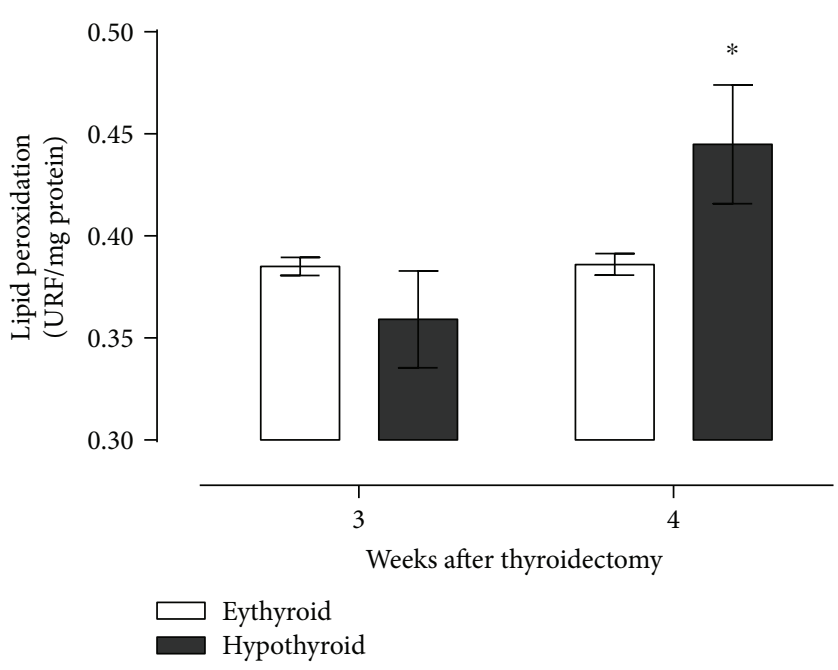

(b)

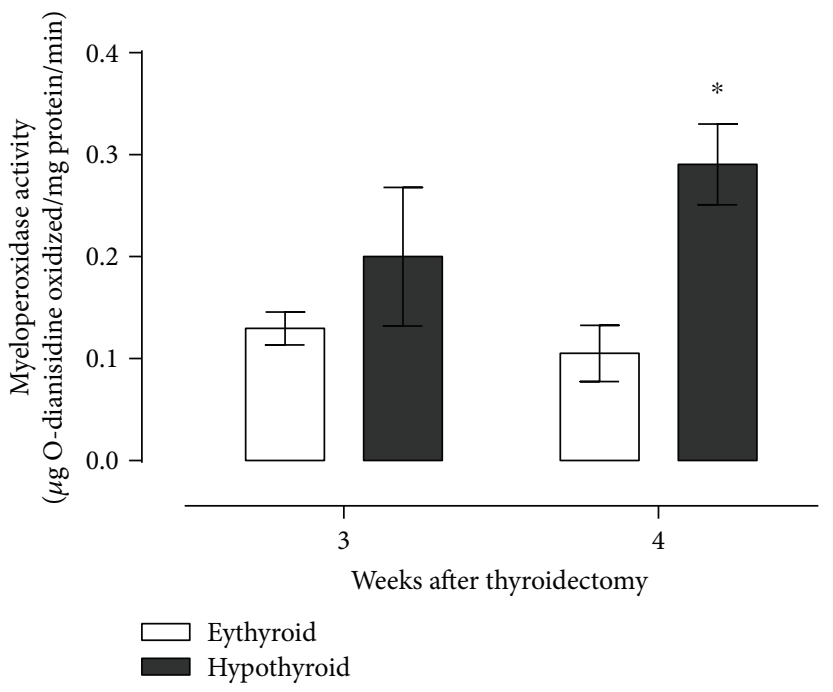

(d)

FIGURE 2: Effect of hypothyroidism on oxidative stress markers reactive oxygen species (a), lipid peroxidation (b), nitrite quantification (c), and myeloperoxidase activity (d). Data are expressed as the mean \pm SEM. ${ }^{*} P<0.05$ versus the euthyroid group $(n=6)$.

there had to be another mechanism involved that occured first but also promoted the development of oxidative stress and the excitotoxicity events found in previous works $[5,6]$. This missed mechanism can be the endoplasmic reticulum stress, which has been established as a common trigger to cell death in several pathologies (and also in normal aging), that includes the development of oxidative stress [33]. The reasons why we thought ERE might be involved are based on the contributions of many studies, where hypothyroidism has been related to peripheral glucose metabolism impairment $[14,34-37]$ and the presence of insulin resistance $[14,15,36]$. In the case of the brain, glucose concentration in cerebral spine fluid or any brain regions had not been assessed; however, glucose transportation from the bloodbrain barrier is decreased during hypothyroidism, as previously reported by Mooradian et al. who found a significative reduction in both mRNA and $55 \mathrm{kDa}$ GLUT1 isoform [13]. Also, other reports have shown that global and regional cerebral blood flux to the hippocampus and other memory-, motor-, attention-, and cognitive-related structures is diminished in hypothyroid patients [12]. As it is well known, brain glucose metabolism depends on thyroid function, which is why hypothyroid patients present with brain hypometabolism, a phenomenon that has been linked with the impairment of memory and cognition [38, 39]. Also, insulin resistance can play an essential role in hypothyroidism-induced cognitive damage, since the normal hippocampus expresses high amounts of GLUT4 transporters, and insulin signaling has recently demonstrated to be necessary for hippocampalmediated memory processes because it increases hippocampal metabolism [40, 41]. Given the impaired glucose delivery to the brain, the diminished glucose intake and metabolism in hypothyroid hippocampal neurons, and the relationship between glucose deprivation and ERE, we determined the expression of markers from the three branches of the UPR and the presence of oxidative stress in the hippocampus of 


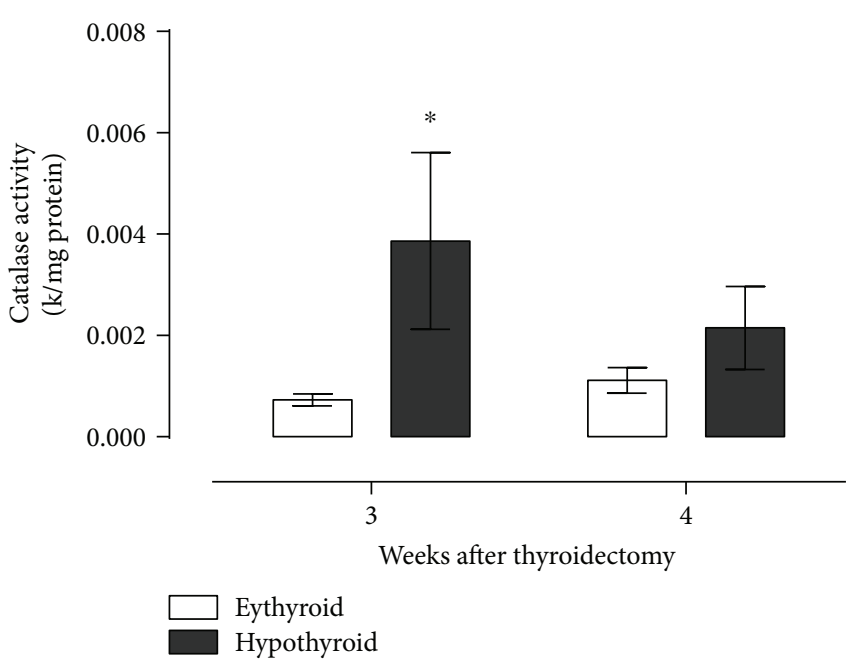

(a)

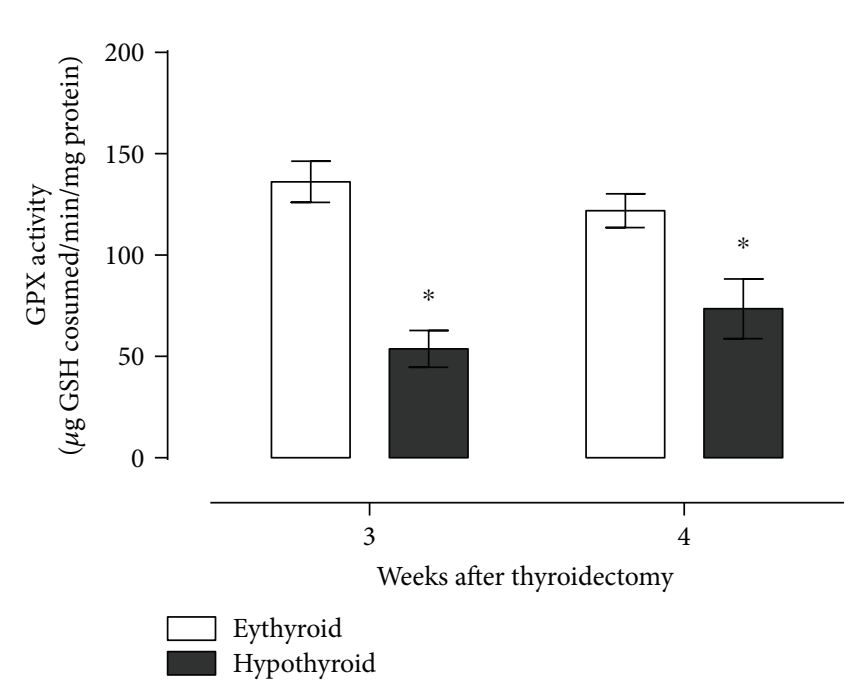

(c)

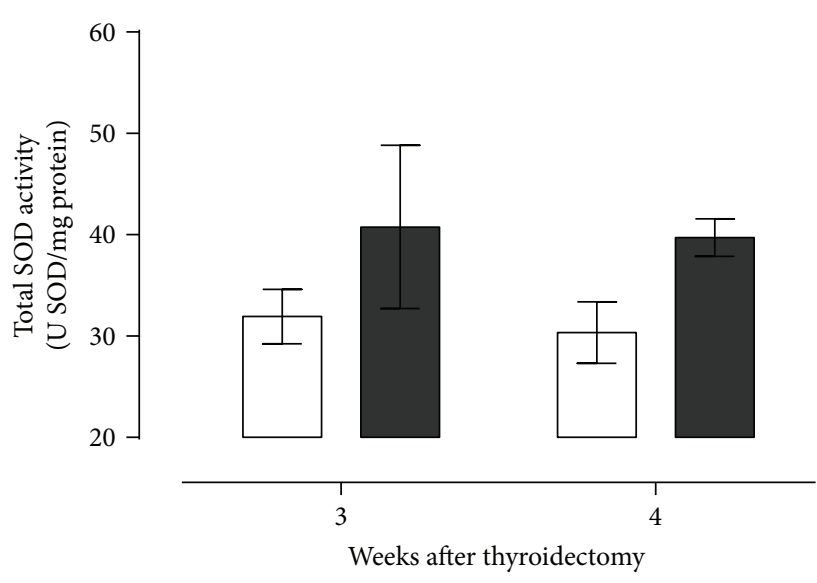

Eythyroid

Hypothyroid

(b)

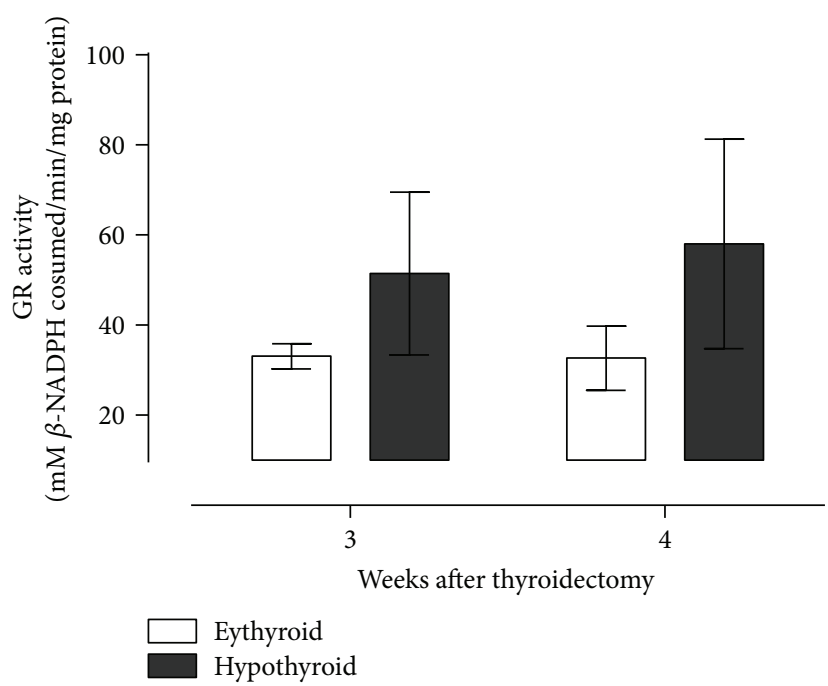

(d)

Figure 3: Activity of antioxidant enzymes catalase (a), superoxide dismutase (b), glutathione peroxidase (c), and glutathione reductase (d) in the hippocampus of thyroidectomized rats. Data are expressed as the mean \pm SEM. ${ }^{*} P<0.05$ versus the euthyroid group $(n=6)$.

TABLE 1: Redox environment alterations in the hippocampus of thyroidectomized rats at different periods of time.

\begin{tabular}{lcccc}
\hline & \multicolumn{2}{c}{ 3rd week } & \multicolumn{2}{c}{ 4th week } \\
& Euthyroid & Hypothyroid & Euthyroid & Hypothyroid \\
\hline GSH ( $\mu$ g GSH/mg protein) & $426.66 \pm 36.16$ & $452.02 \pm 41.76$ & $447.59 \pm 32.35$ & $332.94 \pm 36.16^{* * * *}$ \\
GSSG ( $\mu$ g GSSG/mg protein) & $1.33 \pm 0.25$ & $1.51 \pm 0.22$ & $1.40 \pm 0.19$ & $1.42 \pm 0.19$ \\
Index GSH $/$ GSSG & $145318.53 \pm 27632.49$ & $130329.80 \pm 27632.49$ & $155529.19 \pm 23930.43$ & $76109.75 \pm 27632.49^{* * * *}$ \\
$\gamma$-Glutamyl transpeptidase & $1.27 \pm 0.37$ & $3.04 \pm 0.59^{*}$ & $1.27 \pm 0.37$ & $5.34 \pm 0.59^{*, * *}$ \\
activity (UgGT/min/mg protein) & & & & \\
\hline
\end{tabular}

Values are expressed as the mean \pm SEM. ${ }^{*} P<0.05$ versus the euthyroid group; ${ }^{* *} P<0.05$ versus the third week hypothyroid group $(n=6)$.

hypothyroid rats, three and four weeks after thyroidectomy. We found that PERK branch of the UPR might be partially activated at the third week after thyroidectomy because CREB2 expression was higher in hypothyroid homogenates. The abovementioned is relevant because PERK is the first sensor that activates in the UPR and its downstream activates transcription factor CREB2, which primary interacts with cAMP response elements in DNA to initiate the transcription of genes that codify chaperones, sensors, and other proteins involved in the UPR [42]. Also, CREB2 can interact with the GADD153 promoter (due to its relative homology with c-AMP response elements) and activate its translation [43]. 


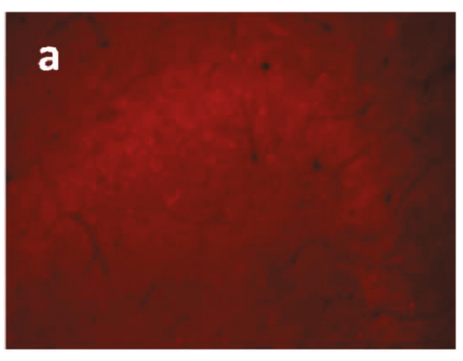

(a)

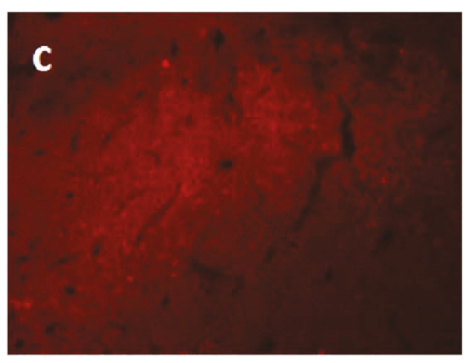

(c)

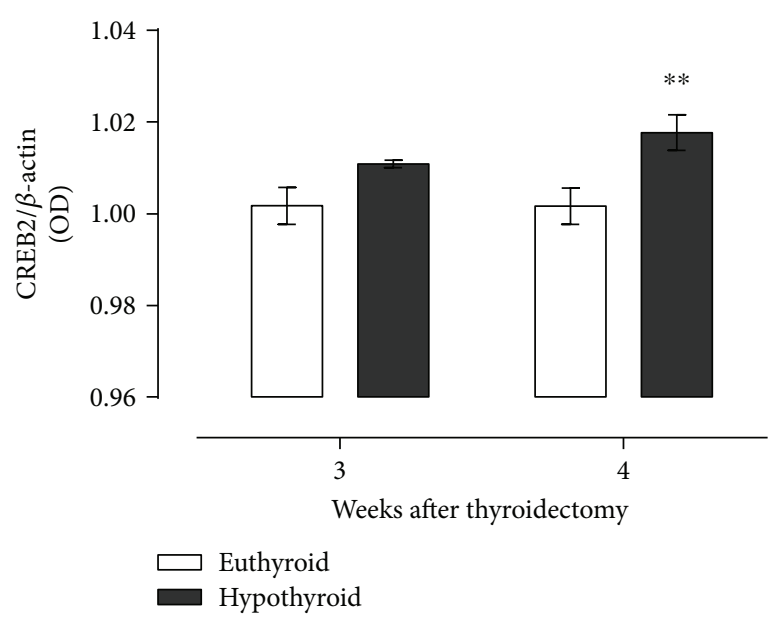

(f)

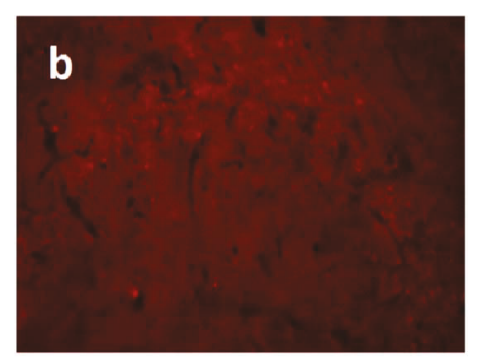

(b)

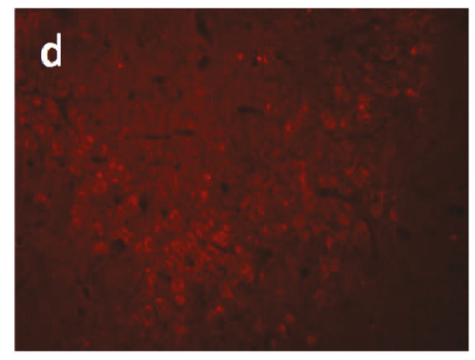

(d)

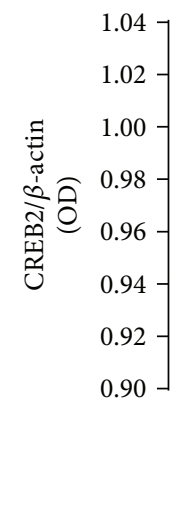

Hypothyroid

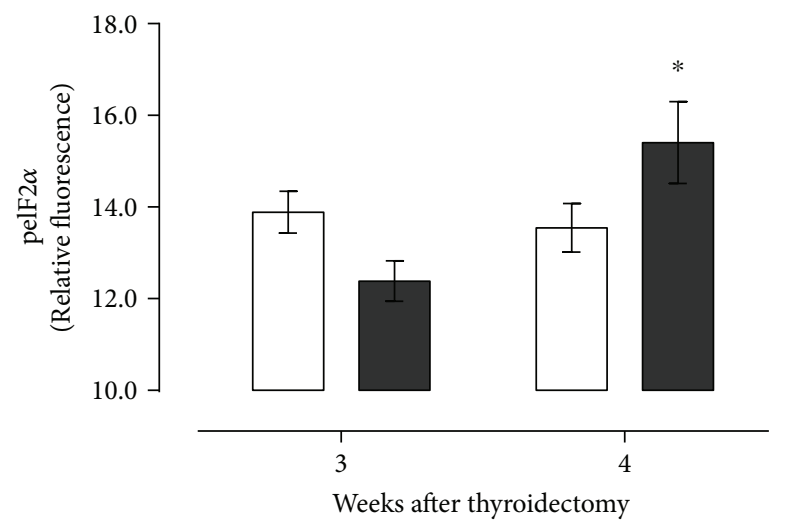

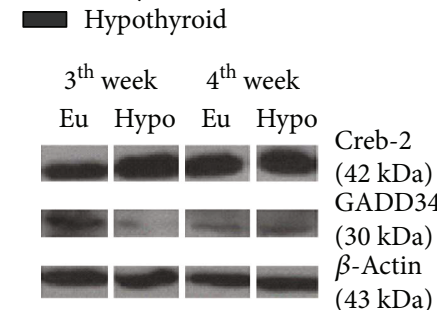

(e)
(43 kDa)

) 


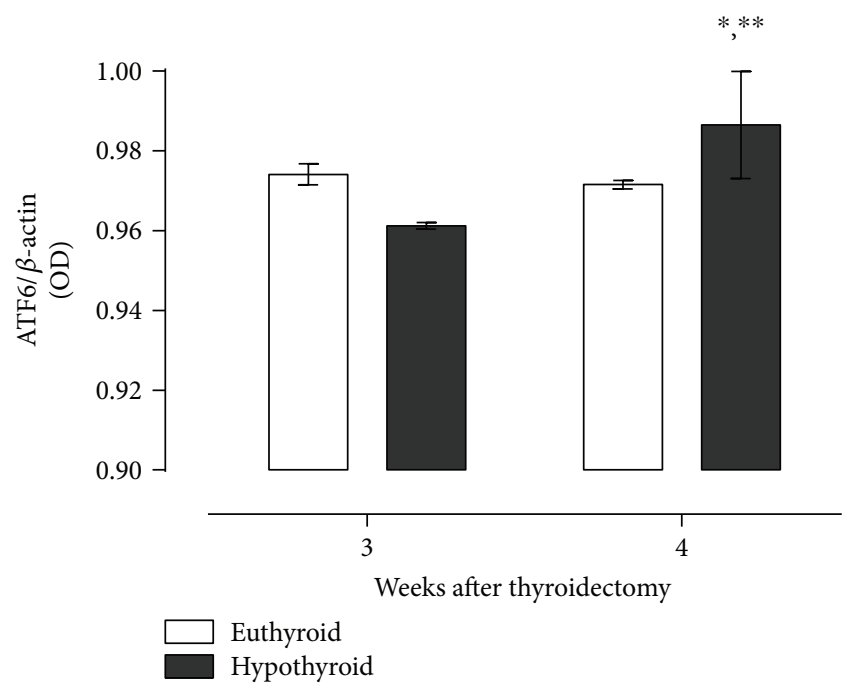

(a)

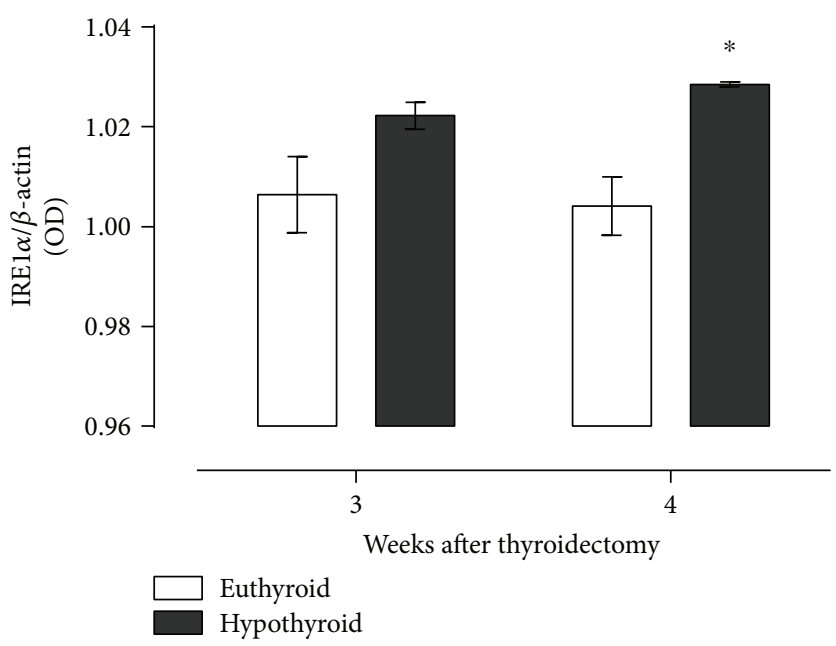

(b)

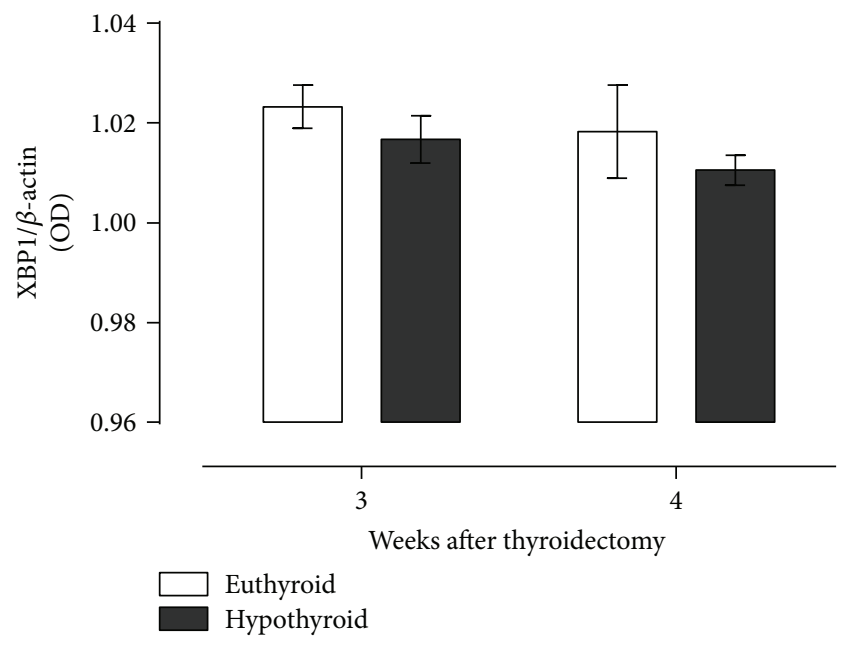

(c)

FIGURE 5: Expression of ATF-6 (a), IRE- $1 \alpha$ (b), and its product of activation XBP-1 (c) in the hippocampus of thyroidectomized rats at different periods of time. Data are expressed as the mean \pm SEM. ${ }^{*} P<0.05$ versus the euthyroid group; ${ }^{* *} P<0.05$ versus the hypothyroid group at the third week $(n=3)$.

process of sulfide-bound formation on the ER, but, that in a maladaptive UPR, can act as an important source of $\mathrm{H}_{2} \mathrm{O}_{2}$ [49]. On the other hand, ERO1 has been linked to calcium cytotoxicity, since it can activate the inositol $(1,4,5)$-trisphosphate receptor type 1 (IP3R1), leading to the massive release of ER calcium to the cell cytoplasm that can activate calcium/ calmodulin-dependent kinase II (CAMKII) which might induce the NADPH oxidase 2 (NOX2), a complex of enzymes in which the primary function is to produce ROS, through the exchange of electrons across membranes to reduce oxygen and form superoxide and other ROS [50]. Given the high expression of these oxidases in the immune cells, especially in phagocytes, and the increased astrogliosis observed in hypothyroidism [51], the activation of NOX2, along with other enzymes like MPO, might be one of the primary sources of ROS and contribute importantly to the establishment of oxidative stress.
For its part, IRE1 performs its prosurvival function through the formation of XBP1s, which heterodimerizes with nuclear factor $\mathrm{Y}$ (NF-Y) and increases translation of proteins involved in the UPR and the endoplasmic reticulumassociated protein degradation (ERAD) [52]. Our results indicate that IRE1 is probably activating its proapoptotic branch. According to that, the kinase dominium of this sensor binds to TRAF2 and recruits to ASK1, leading to the activation of JNK, that phosphorylates ER Bcl-2 and inhibits it, allowing Bax, Bak, and Bim to exert their proapoptotic functions at both ER and mitochondria [53]. It is important to underline that Bax and Bak can activate IRE1 when they directly interact with this sensor [54] and may be an enhancer of this proapoptotic pathway. Also, IRE1 $\alpha$-TRAF2 complex, joined to the calcium released from ER and the direct action of Bax/Bak, can lead to the activation of ER membrane caspase 12 . This caspase can activate mitochondrial-released 


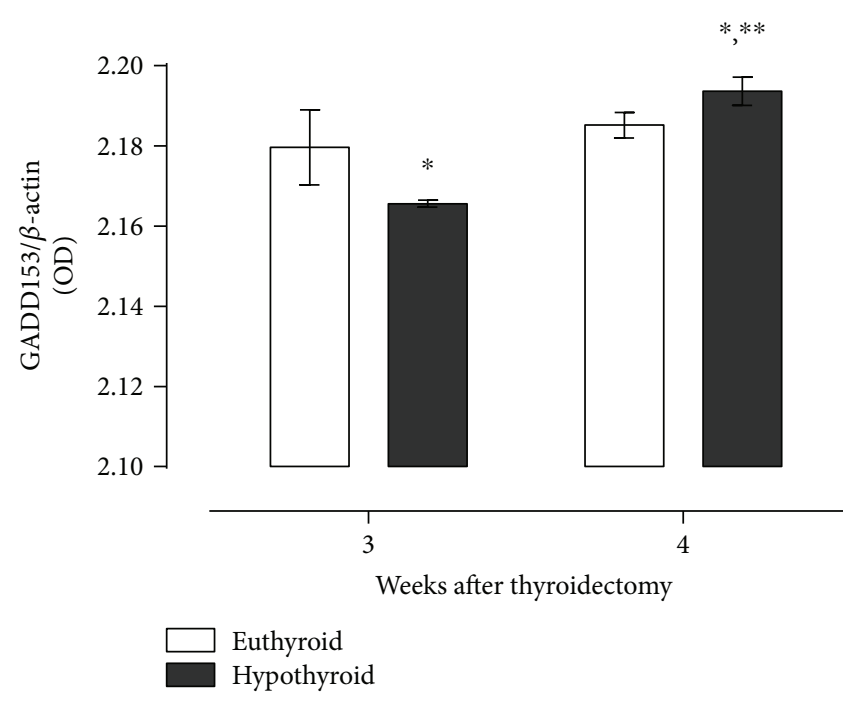

(a)

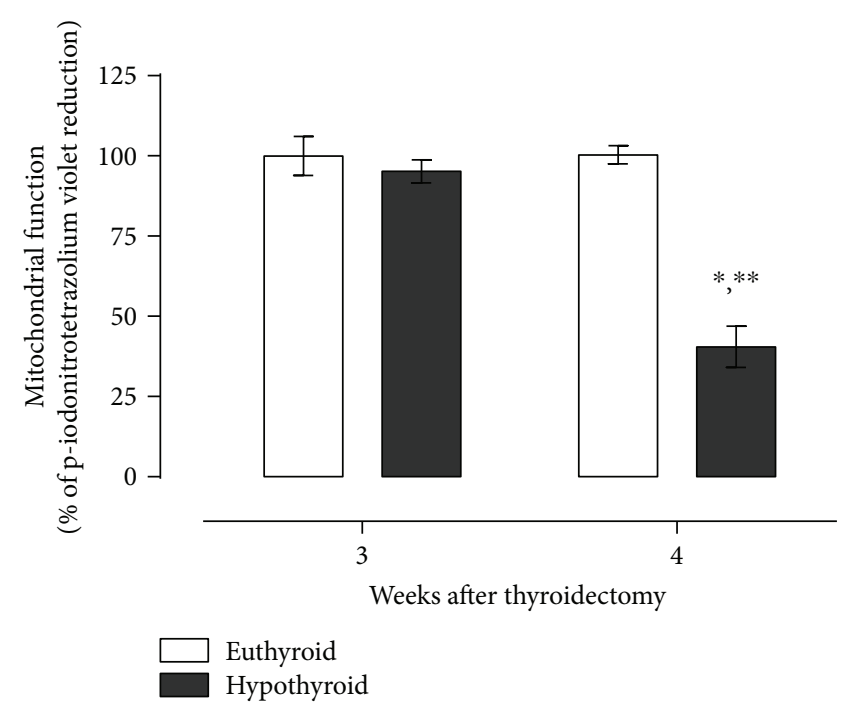

(c)

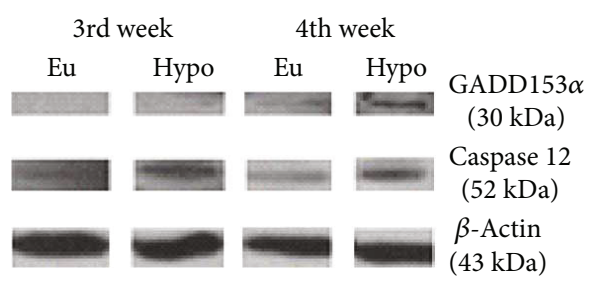

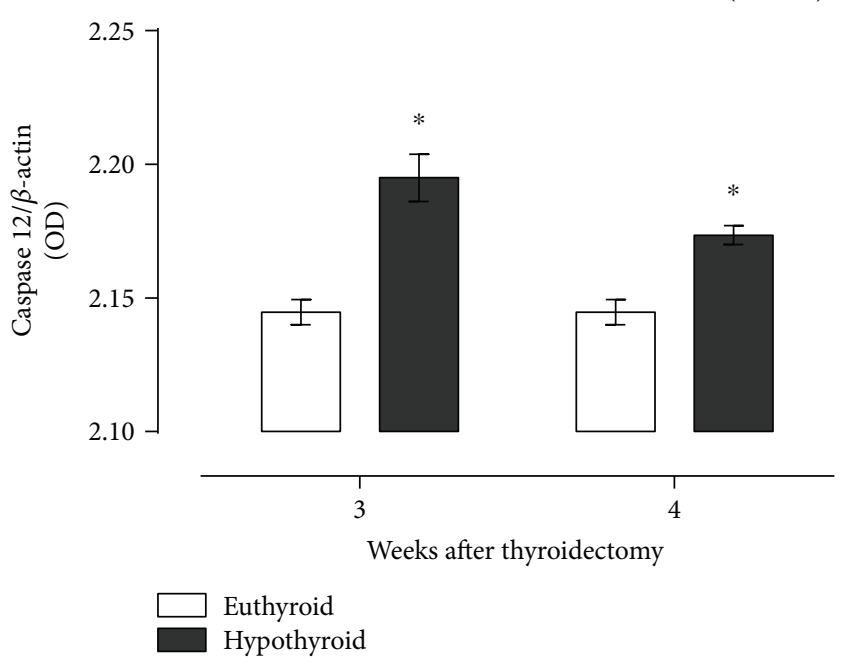

(b)

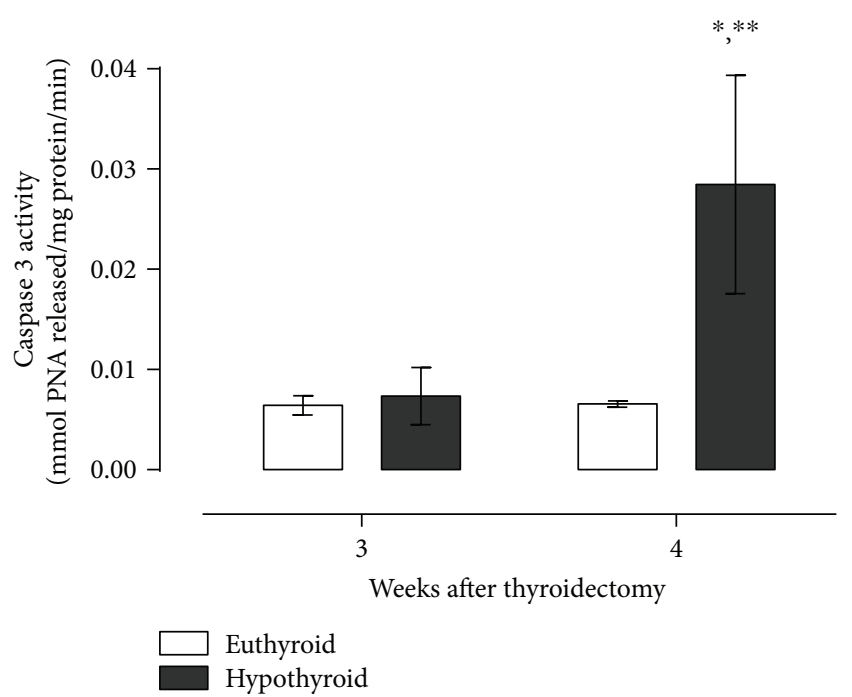

(d)

FIGURE 6: Expression of proapoptotic proteins GADD153 (a) and caspase 12 (b), mitochondrial function (c), and caspase 3 activity (d) in the hippocampus of thyroidectomized rats at different periods of time. Data are expressed as the mean \pm SEM. ${ }^{*} P<0.05$ versus the euthyroid group; ${ }^{* *} P<0.05$ versus the hypothyroid group at the third week (for (a) and (b) $(n=3)$ and for (c) and $\left.(\mathrm{d})(n=6)\right)$.

caspase 9, and both activate effector caspase 3 [9], which we firmly believe happens in hypothyroidism-induced neuronal death in the hippocampus.

Finally, we conclude that endoplasmic reticulum stress is probably the primary mechanism that leads to the death of hippocampal neurons seen in hypothyroidism. We cannot exclude glutamate excitotoxicity as an important hypothyroidism-induced mechanism of neuronal death, and, in fact, we propose it as the next step in this intricate death signaling pathways. More studies will be needed to better elucidate the final death mechanism activated during hypothyroidism, since it can implicate the activation of other pathways than apoptosis and include the participation of the immune system, through the inflammatory response.

\section{Ethical Approval}

All procedures were realized according to applicable international, national, and/or institutional guidelines for the care and use of animals. The authors followed the Helsinki 
declaration, the Mexican laws and codes in the seventh title of the General Law of Health regarding health research, and NOM-062-ZOO-1999 for the handle of laboratory animals. Also, this protocol was approved by the ENCB-IPN Bioethics committee (CEI-ENCB-021/2014).

\section{Conflicts of Interest}

The authors declare that there is no conflict of interest regarding the publication of this article. The researchers are fellows of EDI, COFAA, and SNI.

\section{Acknowledgments}

This study was partially supported by Consejo Nacional de Ciencia y Tecnología (CONACyT) (221057) and SIP-IPN (20171416, 20171284, and 20171152). The authors thank IPN, Secretaría de Investigación y Posgrado-IPN, and Consejo Nacional de Ciencia y Tecnología (CONACyT) for the financial support.

\section{References}

[1] J. R. Garber, R. H. Cobin, H. Gharib et al., "Clinical practice guidelines for hypothyroidism in adults: cosponsored by the American Association of Clinical Endocrinologists and the American Thyroid Association," Thyroid, vol. 22, no. 12, pp. 1200-1235, 2012.

[2] K. H. Alzoubi, N. Z. Gerges, A. M. Aleisa, and K. A. Alkadhi, "Levothyroxin restores hypothyroidism-induced impairment of hippocampus-dependent learning and memory: behavioral, electrophysiological, and molecular studies," Hippocampus, vol. 19, no. 1, pp. 66-78, 2009.

[3] I. M. Baldini, A. Vita, M. C. Mauri et al., "Psychopathological and cognitive features in subclinical hypothyroidism," Progress in Neuro-Psychopharmacology and Biological Psychiatry, vol. 21, no. 6, pp. 925-935, 1997.

[4] M. D. Madeira, N. Sousa, M. T. Lima-Andrade, F. Calheiros, A. Cadete-Leite, and M. M. Paula-Barbosa, "Selective vulnerability of the hippocampal pyramidal neurons to hypothyroidism in male and female rats," The Journal of Comparative Neurology, vol. 322, no. 4, pp. 501-518, 1992.

[5] C. Alva-Sánchez, A. Becerril, B. Anguiano, C. Aceves, and J. Pacheco-Rosado, "Participation of NMDA-glutamatergic receptors in hippocampal neuronal damage caused by adultonset hypothyroidism," Neuroscience Letters, vol. 453, no. 3, pp. 178-181, 2009.

[6] E. Cano-Europa, F. Pérez-Severiano, P. Vergara et al., "Hypothyroidism induces selective oxidative stress in amygdala and hippocampus of rat," Metabolic Brain Disease, vol. 23, no. 3, pp. 275-287, 2008.

[7] P. Ambrogini, R. Cuppini, P. Ferri et al., "Thyroid hormones affect neurogenesis in the dentate gyrus of adult rat," Neuroendocrinology, vol. 81, no. 4, pp. 244-253, 2005.

[8] M. Schröder and R. J. Kaufman, "The mammalian unfolded protein response," Annual Review of Biochemistry, vol. 74, no. 1, pp. 739-789, 2005.

[9] E. Szegezdi, S. E. Logue, A. M. Gorman, and A. Samali, "Mediators of endoplasmic reticulum stress-induced apoptosis," EMBO Reports, vol. 7, no. 9, pp. 880-885, 2006.
[10] S. Abadpour, S. O. Göpel, S. W. Schive, O. Korsgren, A. Foss, and H. Scholz, "Glial cell-line derived neurotrophic factor protects human islets from nutrient deprivation and endoplasmic reticulum stress induced apoptosis," Scientific Reports, vol. 7, no. 1, p. 1575, 2017.

[11] A. Helenius, "How N-linked oligosaccharides affect glycoprotein folding in the endoplasmic reticulum," Molecular Biology of the Cell, vol. 5, no. 3, pp. 253-265, 1994.

[12] Y. Krausz, N. Freedman, H. Lester et al., "Regional cerebral blood flow in patients with mild hypothyroidism," Journal of Nuclear Medicine, vol. 45, no. 10, pp. 1712-1715, 2004.

[13] A. D. Mooradian, W. Girgis, and G. N. Shah, "Thyroid hormone-induced GLUT-1 expression in rat cerebral tissue: effect of age," Brain Research, vol. 747, no. 1, pp. 144-146, 1997.

[14] E. Maratou, D. J. Hadjidakis, A. Kollias et al., "Studies of insulin resistance in patients with clinical and subclinical hypothyroidism," European Journal of Endocrinology, vol. 160, no. 5, pp. 785-790, 2009.

[15] G. Dimitriadis, P. Mitrou, V. Lambadiari et al., "Insulin action in adipose tissue and muscle in hypothyroidism," The Journal of Clinical Endocrinology \& Metabolism, vol. 91, no. 12, pp. 4930-4937, 2006.

[16] C. Leloup, M. Arluison, N. Kassis et al., "Discrete brain areas express the insulin-responsive glucose transporter GLUT4," Molecular Brain Research, vol. 38, no. 1, pp. 45-53, 1996.

[17] M. Pineda-Reynoso, E. Cano-Europa, V. Blas-Valdivia, A. Hernandez-Garcia, M. Franco-Colin, and R. Ortiz-Butron, "Hypothyroidism during neonatal and perinatal period induced by thyroidectomy of the mother causes depressivelike behavior in prepubertal rats," Neuropsychiatric Disease and Treatment, vol. 6, pp. 137-143, 2010.

[18] S. F. Ali, C. P. LeBel, and S. C. Bondy, "Reactive oxygen species formation as a biomarker of methylmercury and trimethyltin neurotoxicity," Neurotoxicology, vol. 13, no. 3, pp. 637-648, 1992.

[19] E. Cano-Europa, G. E. López-Galindo, A. Hernández-García et al., "Lidocaine affects the redox environment and the antioxidant enzymatic system causing oxidative stress in the hippocampus and amygdala of adult rats," Life Sciences, vol. 83, no. 19-20, pp. 681-685, 2008.

[20] K. V. H. Sastry, R. P. Moudgal, J. Mohan, J. S. Tyagi, and G. S. Rao, "Spectrophotometric determination of serum nitrite and nitrate by copper-cadmium alloy," Analytical Biochemistry, vol. 306, no. 1, pp. 79-82, 2002.

[21] S. Fietz, A. Bondzio, A. Moschos, B. Hertsch, and R. Einspanier, "Measurement of equine myeloperoxidase (MPO) activity in synovial fluid by a modified MPO assay and evaluation of joint diseases - an initial case study," Research in Veterinary Science, vol. 84, no. 3, pp. 347-353, 2008.

[22] E. Cano-Europa, V. Blas-Valdivia, M. Franco-Colin, C. A. Gallardo-Casas, and R. Ortiz-Butrón, "Methimazole-induced hypothyroidism causes cellular damage in the spleen, heart, liver, lung and kidney," Acta Histochemica, vol. 113, no. 1, pp. 1-5, 2011.

[23] D. G. Hafeman, R. A. Sunde, and W. G. Hoekstra, "Effect of dietary selenium on erythrocyte and liver glutathione peroxidase in the rat," The Journal of Nutrition, vol. 104, no. 5, pp. $580-587,1974$. 
[24] J. D. Crapo, J. M. McCord, and I. Fridovich, "[41] Preparation and assay of superioxide dismutases," Methods in Enzymology, vol. 53, pp. 382-393, 1978.

[25] P. Askelöf, C. Guthenberg, I. Jakobson, and B. Mannervik, "Purification and characterization of two glutathione S-aryltransferase activities from rat liver," The Biochemical Journal, vol. 147, no. 3, pp. 513-522, 1975.

[26] F. Q. Schafer and G. R. Buettner, "Redox environment of the cell as viewed through the redox state of the glutathione disulfide/glutathione couple," Free Radical Biology \& Medicine, vol. 30, no. 11, pp. 1191-1212, 2001.

[27] G. Paxinos and C. Watson, The Rat Brain in Stereotaxic Coordinates, Academic Press, San Diego, CA, USA, 1998.

[28] D. Elinos-Calderón, Y. Robledo-Arratia, V. Pérez-de la Cruz, J. Pedraza-Chaverrí, S. F. Ali, and A. Santamaría, "Early nerve ending rescue from oxidative damage and energy failure by L-carnitine as post-treatment in two neurotoxic models in rat: recovery of antioxidant and reductive capacities," Experimental Brain Research, vol. 197, no. 3, pp. 287-296, 2009.

[29] H. Carageorgiou, C. Pantos, A. Zarros et al., "Changes in acetylcholinesterase, $\mathrm{Na}^{+}, \mathrm{K}^{+}$-ATPase, and $\mathrm{Mg}^{2+}$-ATPase activities in the frontal cortex and the hippocampus of hyper- and hypothyroid adult rats," Metabolism, vol. 56, no. 8, pp. 1104-1110, 2007.

[30] C. Alva-Sánchez, R.. Ortiz-Butrón, and J. Pacheco-Rosado, "Kainic acid does not affect CA3 hippocampal region pyramidal cells in hypothyroid rats," Brain Research Bulletin, vol. 63, no. 2, pp. 167-171, 2004.

[31] K. B. Sánchez-Huerta, S. Montes, F. Pérez-Severiano, C. AlvaSánchez, C. Ríos, and J. Pacheco-Rosado, "Hypothyroidism reduces glutamate-synaptic release by ouabain depolarization in rat CA3-hippocampal region," Journal of Neuroscience Research, vol. 90, no. 4, pp. 905-912, 2012.

[32] A. Shuaib, S. Ijaz, R. Mazagri et al., "Hypothyroidism protects the brain during transient forebrain ischemia in gerbils," Experimental Neurology, vol. 127, no. 1, pp. 119125, 1994.

[33] J. D. Malhotra and R. J. Kaufman, "Endoplasmic reticulum stress and oxidative stress: a vicious cycle or a double-edged sword?," Antioxidants \& Redox Signaling, vol. 9, no. 12, pp. 2277-2294, 2007.

[34] T. L. Althausen and M. Stockholm, "Influence of the thyroid gland on absorption in the digestive tract," American Journal of Physiology-Legacy Content, vol. 123, no. 3, pp. 577-588, 1938.

[35] M. S. M. Ardawi and S. M. Jalalah, "Effects of hypothyroidism on glucose and glutamine metabolism by the gut of the rat," Clinical Science, vol. 81, no. 3, pp. 347-355, 1991.

[36] A. J. McCulloch, D. G. Johnston, P. H. Baylis et al., "Evidence that thyroid hormones regulate gluconeogenesis from glycerol in man," Clinical Endocrinology, vol. 19, no. 1, pp. 67-76, 1983.

[37] M. J. Müller and H. J. Seitz, "Interrelation between thyroid state and the effect of glucagon on gluconeogenesis in perfused rat livers," Biochemical Pharmacology, vol. 36, no. 10, pp. 1623-1627, 1987.

[38] M. Bauer, D. H. S. Silverman, F. Schlagenhauf et al., "Brain glucose metabolism in hypothyroidism: a positron emission tomography study before and after thyroid hormone replacement therapy," The Journal of Clinical Endocrinology \& Metabolism, vol. 94, no. 8, pp. 2922-2929, 2009.
[39] V. Jahagirdar and E. C. McNay, “Thyroid hormone's role in regulating brain glucose metabolism and potentially modulating hippocampal cognitive processes," Metabolic Brain Disease, vol. 27, no. 2, pp. 101-111, 2012.

[40] S. Babri, H. G. Badie, S. Khamenei, and M. OrdikhaniSeyedlar, "Intrahippocampal insulin improves memory in a passive-avoidance task in male wistar rats," Brain and Cognition, vol. 64, no. 1, pp. 86-91, 2007.

[41] M. Moosavi, N. Naghdi, N. Maghsoudi, and S. Zahedi Asl, "The effect of intrahippocampal insulin microinjection on spatial learning and memory," Hormones and Behavior, vol. 50, no. 5, pp. 748-752, 2006.

[42] H. P. Harding, Y. Zhang, A. Bertolotti, H. Zeng, and D. Ron, "Perk is essential for translational regulation and cell survival during the unfolded protein response," Molecular Cell, vol. 5, no. 5, pp. 897-904, 2000.

[43] T. W. Fawcett, J. L. Martindale, K. Z. Guyton, T. Hai, and N. J. Holbrook, "Complexes containing activating transcription factor (ATF)/cAMP-responsive-element-binding protein (CREB) interact with the CCAAT/enhancer-binding protein (C/EBP)-ATF composite site to regulate Gadd153 expression during the stress response," The Biochemical Journal, vol. 339, no. 1, pp. 135-141, 1999.

[44] H. S. Ghosh, B. Reizis, and P. D. Robbins, "SIRT1 associates with eIF2-alpha and regulates the cellular stress response," Scientific Reports, vol. 1, no. 1, p. 150, 2011.

[45] I. C. Lee, X. Y. Ho, S. E. George et al., "Oxidative stress promotes SIRT1 recruitment to the GADD34/PP1 $\alpha$ complex to activate its deacetylase function," Cell Death \& Differentiation, vol. 25, no. 2, pp. 255-267, 2018.

[46] Y. Ma, J. W. Brewer, J. Alan Diehl, and L. M. Hendershot, "Two distinct stress signaling pathways converge upon the CHOP promoter during the mammalian unfolded protein response," Journal of Molecular Biology, vol. 318, no. 5, pp. 1351-1365, 2002.

[47] K. D. McCullough, J. L. Martindale, L.-O. Klotz, T.-Y. Aw, and N. J. Holbrook, "Gadd153 sensitizes cells to endoplasmic reticulum stress by down-regulating $\mathrm{Bcl} 2$ and perturbing the cellular redox state," Molecular and Cellular Biology, vol. 21, no. 4, pp. 1249-1259, 2001.

[48] S. J. Marciniak, C. Y. Yun, S. Oyadomari et al., "CHOP induces death by promoting protein synthesis and oxidation in the stressed endoplasmic reticulum," Genes \& Development, vol. 18, no. 24, pp. 3066-3077, 2004.

[49] M. Malinouski, Y. Zhou, V. V. Belousov, D. L. Hatfield, and V. N. Gladyshev, "Hydrogen peroxide probes directed to different cellular compartments," PLoS One, vol. 6, no. 1, article e14564, 2011.

[50] G. Li, C. Scull, L. Ozcan, and I. Tabas, "NADPH oxidase links endoplasmic reticulum stress, oxidative stress, and PKR activation to induce apoptosis," The Journal of Cell Biology, vol. 191, no. 6, pp. 1113-1125, 2010.

[51] C. Cortés, E. Eugenin, E. Aliaga et al., "Hypothyroidism in the adult rat causes incremental changes in brain-derived neurotrophic factor, neuronal and astrocyte apoptosis, gliosis, and deterioration of postsynaptic density," Thyroid, vol. 22, no. 9, pp. 951-963, 2012.

[52] H. Yoshida, T. Matsui, A. Yamamoto, T. Okada, and K. Mori, "XBP1 mRNA is induced by ATF6 and spliced by IRE1 in response to ER stress to produce a highly active transcription factor," Cell, vol. 107, no. 7, pp. 881-891, 2001. 
[53] M. C. Bassik, L. Scorrano, S. A. Oakes, T. Pozzan, and S. J. Korsmeyer, "Phosphorylation of BCL-2 regulates ER $\mathrm{Ca}^{2+}$ homeostasis and apoptosis," The EMBO Journal, vol. 23, no. 5, pp. 1207-1216, 2004.

[54] C. Hetz, P. Bernasconi, J. Fisher et al., "Proapoptotic BAX and BAK modulate the unfolded protein response by a direct interaction with IRE1 $\alpha$," Science, vol. 312, no. 5773, pp. 572-576, 2006. 


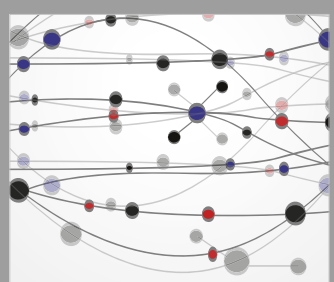

The Scientific World Journal
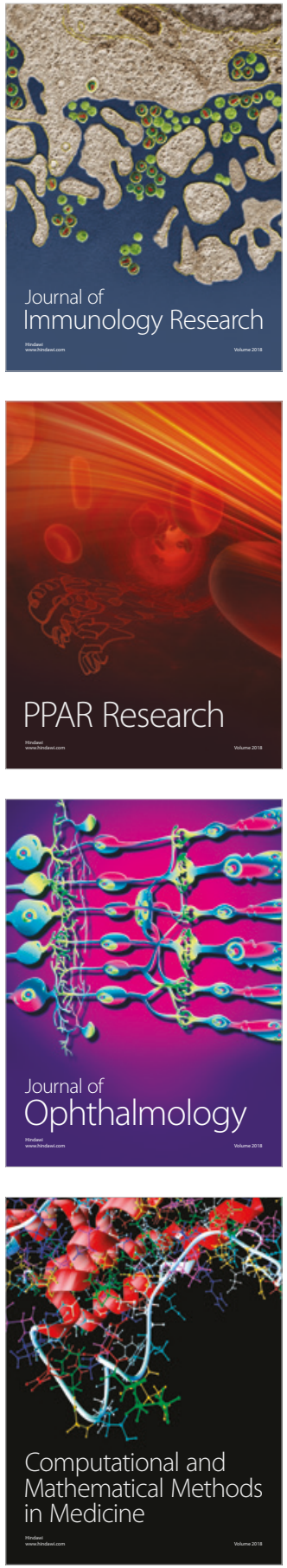

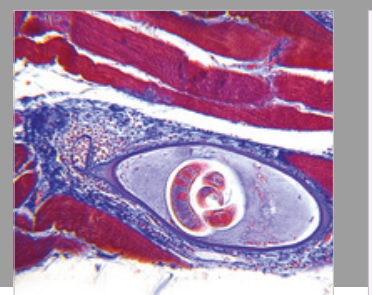

Gastroenterology Research and Practice

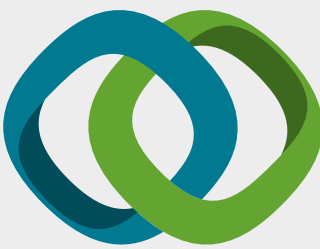

\section{Hindawi}

Submit your manuscripts at

www.hindawi.com
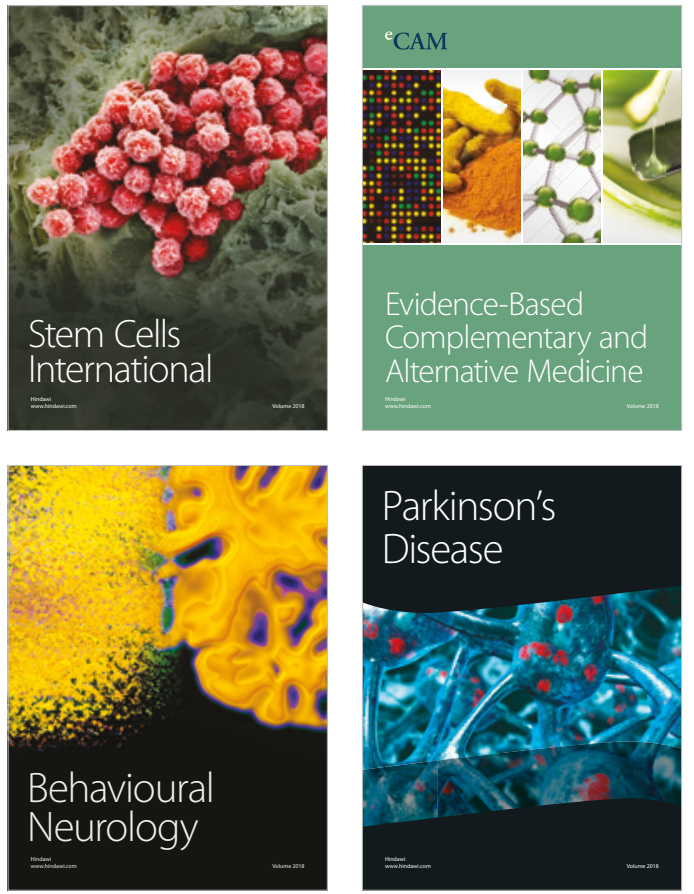

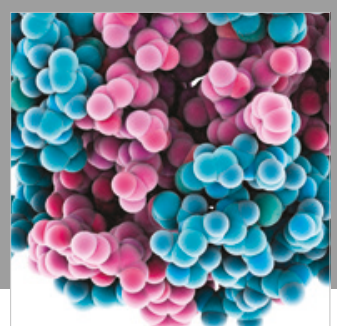

ournal of

Diabetes Research

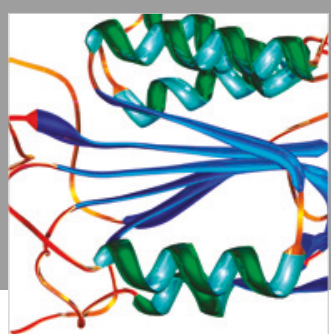

Disease Markers
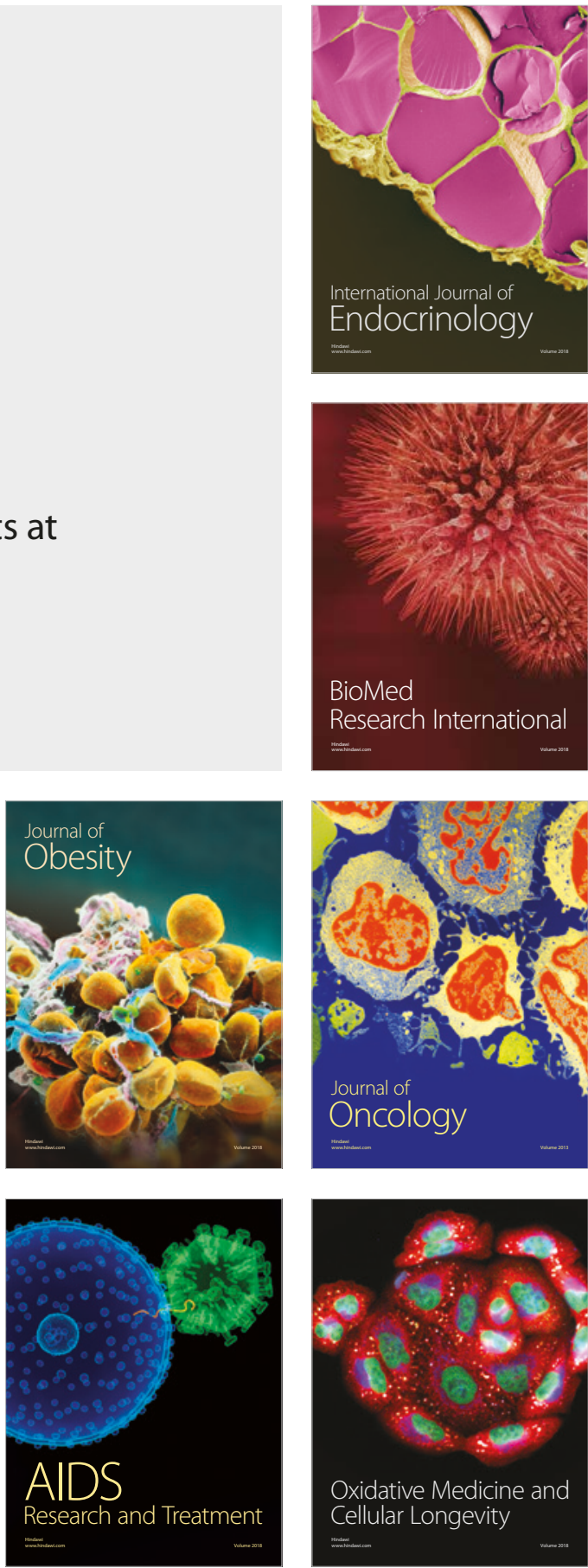